\title{
ATI - Mapping the Future of Testing
}

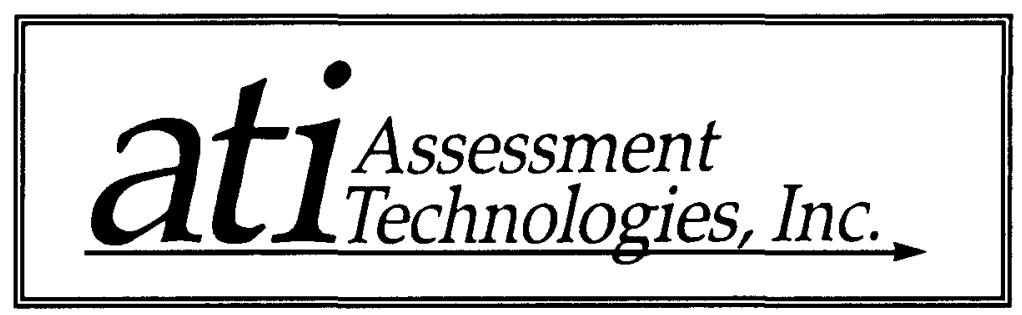

One of the primary functions of the American Board of Family Practice (ABFP) is to certify and recertify family physicians. In an effort to improve the evaluation of family physicians, the Board created a subsidiary in 1997 devoted to developing and implementing state-of-the-art examinations by incorporating the most modern technology available.

\section{Testing Subsidiary Formed}

This new subsidiary, Assessment Technologies, Inc. (ATI), is based in Lexington, $\mathrm{Ky}$, and is a forprofit division of the ABFP's Family Practice Technologies, Inc. ATI is charged with the responsibility of developing computer-based certification and recertification examinations for the ABFP, and developing and supporting computerbased testing administration systems.

ATI is governed by a 7-member board of directors including Robert Avant, MD, Executive Director of the ABFP, who serves as president, and Paul Young, MD, former executive director of the ABFP, who serves as chairman of the board.

The professional staff of ATI consists of two distinct divisions. The Technical Division is headed by Richard Rovinelli, PhD, Vice President of Technical Development. The Medical Knowledge and Data Base Division is led by Michael D. Hagen, MD, Project Director and Secretary/Treasurer of ATI. Robert J. Cattoi, Executive Director of the Pisacano Memorial Foundation, serves as chief financial officer and chief operating officer.

\section{Examinees Numbers Increasing}

The ABFP's certification and recertification examinations have been taken by thousands of physi- cians annually since 1970 and 1976. Most recently, in 1998, 3734 physicians took the certification examinations and 6387 physicians took the recertification examinations. These numbers are an increase of 48 percent during the past 10 years and 36 percent during the past 5 years.

\section{Exceed Industry Standards}

Since its founding, the ABFP has constantly striven to develop and improve upon its examination system for family practice certification and recertification. The Board has always taken seriously their position that their examination methods, presentations, and questions must meet and exceed industry standards and at the same time provide appropriate testing sites for physicians.

\section{Goal: Improve the Examination}

During the years the Board has been developing and administering the examinations, it has annually reviewed its methods and the materials presented. It has been the goal of the Board to create an examination that would comprehensively assess the following physician skills:

- Clinical problem-solving abilities

- Cognitive knowledge

- Management of a patient's problem over time

With the advent of low-cost and more powerful personal computers, it became apparent to the Board that there could be an improved method of testing by incorporating this technology. The Board has been working on this methodology since 1992 and anticipates that it will unveil a prototype of the computer-based test in the near future. 


\section{Result: A More Comprehensive Test}

This computer-based examination will provide a better assessment of the physicians' knowledge by allowing the candidates to work through specific case scenarios. They will accomplish this by doing the following:

- Taking a patient's history

- Completing a physical examination

- Ordering and reviewing tests and making a treatment plan

The patient's clinical profiles will be designed to evolve with time so that the physicians' actions can be monitored.

The Board believes that this will be a more comprehensive test for the physician as opposed to the current paper and pencil test, which gives clinical vignettes and only a snapshot of the physicians' clinical ability in a specific scenario.

\section{EVOLUTION OF ATI}

\section{First: Build a Technical Model}

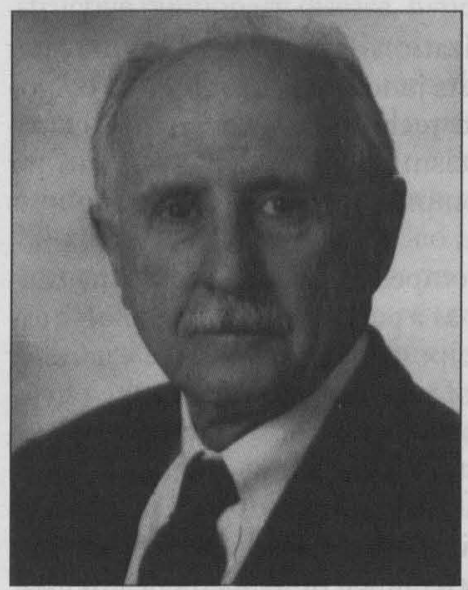

Richard Rovinelli, $\mathrm{PhD}$ built the computer-based test technical model and is responsible for the computerized test administration system.

In 1992 Richard Rovinelli, PhD, who has been associated with the ABFP since 1976, was asked to explore the possibility of using the computer to provide more evaluative data for the examinees. In response, a project was initiated to build a technical model of computer-based testing and administration. In 1996 it became apparent that the test could be further enhanced by incorporating medical knowledge bases and databases in the examination's prototype.

This presented two issues for the Board to address. The first was to find a physician who had family practice experience and who knew how to develop the medical knowledge bases and databases needed for their computer-testing format. The second issue was to determine how to bring the prototype version to successful production.
Second: Build Medical Knowledge and Databases In 1996 the ABFP Board hired former ABFP president and family physician, Michael Hagen, MD.

Dr. Hagen has brought medical knowledge base and database gathering and management experience to complement Dr. Rovinelli's technical expertise to create the compu-

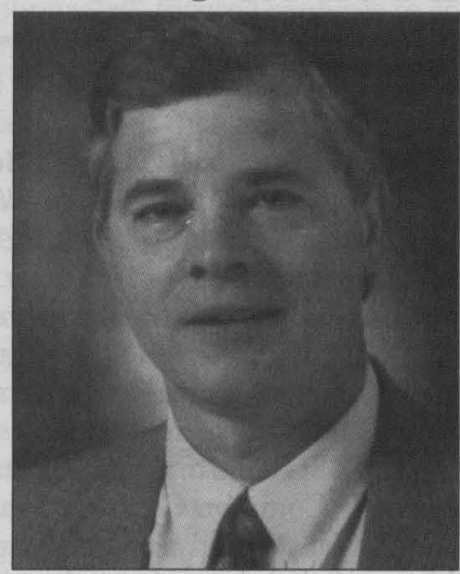

Michael Hagen, MD is charged with gathering and managing the medical knowledge and data bases. ter-based testing model that is nearing completion.

\section{Third: New Opportunities}

While ATI's development team successfully completed the fundamental goals set forth by the Board for its computer-based testing prototype, it became obvious that it also presented an excellent opportunity to develop software that could be of assistance to other American Board of Medical Specialties (ABMS) member boards for their computerized test administration. This computerized test administration system consists of the following components:

- Administration and registration

- Item banking

- Test presentation

- Test scoring and analysis

- A reporting component

- A utilities component

After ATI's initial presentation, a number of ABMS boards have expressed interest in this computerized test administration technology. The American Board of Pathology is currently using it with some of their examinations.

This is an exciting time for the development of the examination and its capabilities, especially with the advancements of medical and computer technology.

It is conceivable that in the future the test will utilize voice recognition and digitized images and will allow an examination of a patient in a virtual reality setting. 